\title{
Experience-Based Swedish TTO and VAS Value Sets for EQ-5D-5L Health States
}

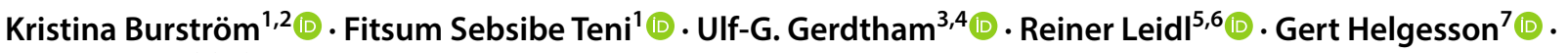 \\ Ola Rolfson ${ }^{1,8,9,10} \cdot$ Martin Henriksson $^{11}$ (i)
}

Published online: 20 April 2020

(c) The Author(s) 2020

\begin{abstract}
Background and Objective Although value sets for the five-level version of the generic health-related quality-of-life instrument EQ-5D are emerging, there is still no value set available in the literature based on time trade-off valuations made by individuals experiencing the valued health states. The aim of this study was to estimate experience-based value sets for the EQ-5D-5L for Sweden using time trade-off and visual analogue scale valuation methods.

Methods In a large, cross-sectional, population-based, self-administered postal health survey, the EQ-5D-5L descriptive system, EQ visual analogue scale and a time trade-off question were included. Time trade-off and visual analogue scale valuations of the respondent's current health status were used in statistical modelling to estimate a single-index value of health for each of the 3125 health states. Ordinary least-squares and generalised linear models were estimated with the main effect within each of the five dimensions represented by 20 dummy variables reflecting the additional decrement in value for levels 2-5 when the severity increases by one level sequentially beginning from having no problem. Interaction variables representing the occurrence of severity levels in at least one of the dimensions were tested: severity level 2 or worse (N2); severity level 3 or worse (N3); severity level 4 or worse (N4); severity level 5 (N5).

Results A total of 896 health states ( $28.7 \%$ of the 3125 possible EQ-5D-5L health states) were reported by the 25,867 respondents. Visual analogue scale $(n=23,899)$ and time trade-off $(n=13,381)$ responders reported valuations of their currently experienced health state. The preferred regression models used ordinary least-squares estimation for both time trade-off and visual analogue scale values and showed consistency in all coefficients after combining certain levels. Levels 4 and 5 for the dimensions of mobility, self-care and usual activities were combined in the time trade-off model. Including the interaction variable N5, indicating severity level 5 in at least one of the five dimensions, made it possible to distinguish between the two worst severity levels where no other dimension is at level 5 as this coefficient is applied only once. In the visual analogue scale regression model, levels 4 and 5 of the mobility dimension were combined. The interaction variables N2-N4 were included, indicating that each of these terms reflect a statistically significant decrement in visual analogue scale value if any of the dimensions is at severity level 2,3 or 4 , respectively.

Conclusions Time trade-off and visual analogue scale value sets for the EQ-5D-5L are now available for Sweden. The time trade-off value set is the first such value set based on experience-based time trade-off valuation. For decision makers with a preference for experience-based valuations of health states from a representative population-based sample, the reported value sets may be considered fit for purpose to support resource allocation decision as well as evaluating population health and healthcare performance.
\end{abstract}

\section{Introduction}

Electronic supplementary material The online version of this article (https://doi.org/10.1007/s40273-020-00905-7) contains supplementary material, which is available to authorized users.

Kristina Burström

kristina.burstrom@ki.se

Extended author information available on the last page of the article
The generic health-related quality-of-life instrument EQ-5D has been widely used to estimate the quality-of-life component in quality-adjusted life-years and to measure population health and healthcare performance. The original EQ-5D-3L version of the instrument, with five dimensions and three levels of severity for each dimension [1], has more recently 


\section{Key Points for Decision Makers}

Experience-based EQ-5D-5L value sets based on the time trade-off method are not reported in the literature

This work presents experience-based time trade-off and visual analogue scale EQ-5D-5L value sets for Sweden based on data from a large population-based survey

The anxiety/depression dimension had the greatest impact on both time trade-off and visual analogue scale values

Experience-based EQ-5D-5L value sets for decision makers with a preference for experience-based valuations of health states from a representative populationbased sample are now available for use in economic evaluations and health-related quality-of-life studies

been developed into the EQ-5D-5L with the same dimensions, but with five levels of problem restrictions rather than three [2], defining 3125 health states compared with 243 for the EQ-5D-3L. This development was undertaken to accommodate concerns that the EQ-5D-3L version is not granular enough to discriminate between milder health problems and to identify small changes in health status. There is also a difference in the wording for the mobility dimension as the most severe level is "I am unable to walk about" in the EQ-5D-5L compared to "I am confined to bed" in the EQ5D-3L. There are plenty of value sets, i.e. single-index values for the health states defined by the EQ-5D, available for the EQ-5D-3L version of the instrument, and value sets for the EQ-5D-5L version are emerging in the literature [3-5], sometimes not without controversy as concerns about the quality and reliability of the data collected and the methods used in the modelling have been raised in the valuation study in England, one of the first studies conducted [6, 7].

In determining values for the health states defined by the EQ-5D, methods of valuation as well as the source of the valuations must be considered. Regarding the former, value sets based on the rating scale may be considered useful when jurisdictions in their decisions focus on clinical endpoints, whereas choice-based value sets may be preferred for quality-adjusted life-year calculations [8]. A number of jurisdictions are informing their decisions on value sets based on general population valuations of hypothetical health states, for example, the National Institute for Health and Care Excellence in the UK [9]. In contrast, the Swedish Dental and Pharmaceutical Benefits Agency responsible for the reimbursement of prescription drugs in Sweden, explicitly states that experience-based rather than hypothetical values are preferred $[10,11]$. Still, most applied economic evaluations in Sweden, including those submitted to the Swedish Dental and Pharmaceutical Benefits Agency, have used the UK version of the EQ-5D-3L value set, even though the underlying preferences were elicited from an English, Scottish and Welsh population valuing hypothetical health states back in 1993 [12].

It seems reasonable that up-to-date values obtained in a Swedish setting should be used when applying the EQ-5D instrument in a Swedish decision-making context. To achieve this, we previously developed value sets based on valuations obtained from the Swedish general population for the EQ-5D-3L version [13]. For the more recent EQ-5D-5L version, no value sets are available for Sweden. The UK value set for the EQ-5D-3L version has for a long time been a clear candidate to use for other countries [12]. Without such a clear value set candidate for the EQ-5D-5L version, the value sets presented herein ought to have potential for widespread use and acceptance.

In the present study, the respondents value the health state they are currently experiencing. The current health state of a respondent reflects a clearly defined reference of experience, as experience can also be derived from observing the health states of others [14]. Both the visual analogue scale (VAS), rendering a direct valuation of the health state, and the time trade-off (TTO) method, rendering a preferencebased valuation, are employed. Experience-based value sets for the EQ-5D have been estimated for several countries, both for the EQ-5D-3L version [13, 15, 16] and the EQ5D-5L version [17]. They have further been tested and used in several disease areas (for a brief overview, see Leidl and Reitmeir [17]).

The aim of this present work was to estimate TTO and VAS value sets for the EQ-5D-5L for Sweden based on individuals with experience of the valued health states. The contribution of this work is primarily Swedish value sets for the EQ-5D-5L, but it will also add methodological and conceptual aspects to the emerging EQ-5D-5L value set literature by providing the first such value set based on experience-based TTO valuations [18]. In a large population survey, valuations of the respondent's current health status were used in statistical modelling to estimate a single-index value of health for each health state of the EQ-5D-5L version of the instrument.

\section{Methods}

\subsection{Study Population and Material}

This study employed data from the cross-sectional population-based health survey, Life \& Health 2017, conducted in 2017 in the regions/county councils of Uppsala, Sörmland, Västmanland, Värmland and Örebro in Sweden (CDUST 
Region) [19]. The sampling method is described in the Electronic Supplementary Material (ESM). The sociodemographic composition of the CDUST Region resembles overall data from Sweden with respect to the proportion of men and women, age, educational level and median income (Table S1 of the ESM1). The national average age was 41.2 years and ranged from 40.1 to 49.7 years (average 43.1 years) in the studied regions. The national proportion of low educational level was $21.2 \%$ among men and $19.0 \%$ among women; the corresponding proportions ranged from 19.3 to $24.6 \%$ among men and from 16.5 to $23.2 \%$ among women in the studied regions. The national median income for men and women was SEK 256,600, and ranged from SEK 235,500 to SEK 260,700 in the studied regions.

The self-administered postal questionnaires included questions on living conditions, health-related behaviours and health, and were tailored according to content into three age groups; 18-29, 30-69, and 70 years and above. Data used in the present study thus include VAS responses in the ages $30-104$ years $(n=23,899)$ and TTO responses in the ages $30-69$ years $(n=13,381)$. Neither the VAS nor the TTO question was included in the questionnaire to the 18-29-year-old age group and the TTO was not included to those aged 70 years and above (see Figs. S1-S2 of the ESM1).

The pseudonymised data are based on information from individuals who agreed to participate after having been informed about the study. The survey has been approved by the Regional Ethical Review Board in Uppsala (Dnr: 2015/417). The present study has been approved by the Swedish Ethical Review Authority (Dnr: 2019-00763).

\subsubsection{EQ-5D-5L Descriptive System}

Respondents classify their own health into five dimensions (mobility; self-care; usual activities; pain/discomfort; anxiety/depression) and five levels of severity [problems] (no; slight; moderate; severe; extreme/unable to), which describes $3125\left(5^{5}\right)$ unique health profiles or health states [2].

\subsubsection{Time Trade-Off Valuation}

The TTO response option consisted of a horizontal line representing 0-10 years (every year was marked and labelled $0,1,2 \ldots, 10$ years and every half year was marked, but not labelled) and the question read: "Imagine that you are told that you have 10 years left to live. In connection with this you are also told that you can choose to live these years in your current health state or that you can choose to give up some life years to live for a shorter time period in full health." The respondent was asked to indicate the number of years $(x)$ in full health that would be of equal value to
10 years in their current health state on the response option provided. Below the line, there was an additional sentence in parenthesis: "if you think that you currently have full health, you should mark 10 years". The individual TTO value was obtained by dividing the response to the TTO question by 10. Such an open-ended TTO question for currently experienced health was used for the TTO value set for EQ-5D-3L in Sweden [13], and similar versions have been employed in other studies [20-23].

\subsubsection{Visual Analogue Scale Valuation}

With the EQ VAS, respondents rated their own overall health between 100 (best imaginable health) and 0 (worst imaginable health).

\subsection{Modelling}

Each respondent valued one health state, their own current health state, using the TTO and the VAS methods for valuation. EQ-5D-5L dimensions were regressed on individual TTO and VAS values as dependent variables to develop one value set through each valuation method. The independent variables are the five EQ-5D-5L dimensions at the different severity, or problem, levels.

\subsection{Models Assessed}

Regression models through ordinary least-squares (OLS) models and generalised linear models (GLMs) were estimated on TTO and VAS values to develop the value sets. Table 1 presents variables and specifications employed in the different models. The modelling of TTO values assessed five OLS models and four GLMs (through binomial distribution with logit link function). The main effect within each of the five EQ-5D-5L dimensions was represented by 20 dummy variables reflecting the additional decrement in value for levels 2-5 when the severity increases by one level sequentially beginning from having no problem (Model 1). Interaction variables were created representing the occurrence of severity levels in at least one of the dimensions: severity level 2 or worse (N2); severity level 3 or worse (N3); severity level 4 or worse (N4); severity level 5 (N5). In addition to the main effects, the variables N2-N5 were added (Model 2). Monotonicity was expected, i.e. that the ordinal nature of the severity levels within each dimension should be reflected in the regressions. In the TTO analyses using OLS, such inconsistencies were found between severity levels 4 and 5 in the mobility, self-care and usual activities dimensions. We combined levels 4 and 5 (Model 3 ), added the variables N2-N5 (Model 4) and included only N5 (Model 5) in the regressions. In all the OLS models, robust standard errors were reported because of potential 
Table 1 Models assessed

\begin{tabular}{|c|c|}
\hline TTO models & Functions \\
\hline OLS, Model 1 & f (MO2 MO3 MO4 MO5 SC2 SC3 SC4 SC5 UA2 UA3 UA4 UA5 PD2 PD3 PD4 PD5 AD2 AD3 AD4 AD5) \\
\hline OLS, Model 2 & $\begin{array}{l}\text { f (MO2 MO3 MO4 MO5 SC2 SC3 SC4 SC5 UA2 UA3 UA4 UA5 PD2 PD3 PD4 PD5 AD2 AD3 AD4 AD5 N2 } \\
\text { N3 N4 N5) }\end{array}$ \\
\hline OLS, Model 3 & f (MO2 MO3 MO4 SC2 SC3 SC4 UA2 UA3 UA4 PD2 PD3 PD4 PD5 AD2 AD3 AD4 AD5) \\
\hline OLS, Model 4 & f (MO2 MO3 MO4 SC2 SC3 SC4 UA2 UA3 UA4 PD2 PD3 PD4 PD5 AD2 AD3 AD4 AD5 N2 N3 N4 N5) \\
\hline OLS, Model 5 & f (MO2 MO3 MO4 SC2 SC3 SC4 UA2 UA3 UA4 PD2 PD3 PD4 PD5 AD2 AD3 AD4 AD5 N5) \\
\hline GLM (constraint), Model 6 & f (MO2 MO3 MO4 MO5 SC2 SC3 SC4 SC5 UA2 UA3 UA4 UA5 PD2 PD3 PD4 PD5 AD2 AD3 AD4 AD5) \\
\hline GLM (constraint), Model 7 & $\begin{array}{l}\text { f (MO2 MO3 MO4 MO5 SC2 SC3 SC4 SC5 UA2 UA3 UA4 UA5 PD2 PD3 PD4 PD5 AD2 AD3 AD4 AD5 N2 } \\
\text { N3 N4 N5) }\end{array}$ \\
\hline GLM (constraint), Model 8 & $\begin{array}{l}\text { f (MO2 MO3 MO4 MO5 SC2 SC3 SC4 SC5 UA2 UA3 UA4 UA5 PD2 PD3 PD4 PD5 AD2 AD3 AD4 AD5 N3 } \\
\text { N5) }\end{array}$ \\
\hline GLM (constraint), Model 9 & f (MO2 MO3 MO4 MO5 SC2 SC3 SC4 SC5 UA2 UA3 UA4 UA5 PD2 PD3 PD4 PD5 AD2 AD3 AD4 AD5 N5) \\
\hline VAS models & Functions \\
\hline OLS, Model 1 & f (MO2 MO3 MO4 MO5 SC2 SC3 SC4 SC5 UA2 UA3 UA4 UA5 PD2 PD3 PD4 PD5 AD2 AD3 AD4 AD5) \\
\hline OLS, Model 2 & $\begin{array}{l}\text { f (MO2 MO3 MO4 MO5 SC2 SC3 SC4 SC5 UA2 UA3 UA4 UA5 PD2 PD3 PD4 PD5 AD2 AD3 AD4 AD5 N2 } \\
\text { N3 N4 N5) }\end{array}$ \\
\hline OLS, Model 3 & f (MO2 MO3 MO4 SC2 SC3 SC4 SC5 UA2 UA3 UA4 UA5 PD2 PD3 PD4 PD5 AD2 AD3 AD4 AD5) \\
\hline OLS, Model 4 & $\begin{array}{l}\text { f (MO2 MO3 MO4 SC2 SC3 SC4 SC5 UA2 UA3 UA4 UA5 PD2 PD3 PD4 PD5 AD2 AD3 AD4 AD5 N2 N3 N4 } \\
\text { N5) }\end{array}$ \\
\hline OLS, Model 5 & f (MO2 MO3 MO4 SC2 SC3 SC4 SC5 UA2 UA3 UA4 UA5 PD2 PD3 PD4 PD5 AD2 AD3 AD4 AD5 N2 N3 N4) \\
\hline GLM (constraint), Model 6 & f (MO2 MO3 MO4 MO5 SC2 SC3 SC4 SC5 UA2 UA3 UA4 UA5 PD2 PD3 PD4 PD5 AD2 AD3 AD4 AD5) \\
\hline GLM (constraint), Model 7 & $\begin{array}{l}\text { f (MO2 MO3 MO4 MO5 SC2 SC3 SC4 SC5 UA2 UA3 UA4 UA5 PD2 PD3 PD4 PD5 AD2 AD3 AD4 AD5 N2 } \\
\text { N3 N4 N5) }\end{array}$ \\
\hline GLM (constraint), Model 8 & f (MO2 MO3 MO4 MO5 SC2 SC3 SC4 SC5 UA2 UA3 UA4 UA5 PD2 PD3 PD4 PD5 AD2 AD3 AD4 AD5 N5) \\
\hline
\end{tabular}

Variable definitions: MO_2: 1 if mobility at level 2, 3, 4 or 5; 0 otherwise; MO_3: 1 if mobility at level 3, 4 or 5; 0 otherwise; MO_4: 1 if mobility at level 4 or 5; 0 otherwise; MO_5: 1 if mobility at level 5; 0 otherwise. SC_2/3/4/5, UA_2/3/4/5, PD_2/3/4/5 and AD_2/3/4/5 were defined in the same manner as MO_2/3/4/5

GLM generalised linear model, $O L S$ ordinary least squares, TTO time trade-off, VAS visual analogue scale

heteroscedasticity. Among the models assessed, Models 3 and 5 were selected as candidates for further testing of their predictive performance as they both fulfilled the requirement of monotonicity.

GLMs were assessed in addition to OLS models as they were shown to provide better predictive performance among candidate models in the development of experience-based EQ-5D-3L and EQ-5D-5L value sets for Germany, a binomial distribution with a log link ensures precise estimates, which only vary between zero and unity $[15,17]$. The GLMs included the main effects with the 20 dummy variables (Model 6), the variables N2-N5 added (Model 7), the main effects and N3 and N5 added (Model 8), and only N5 added (Model 9). The GLMs were developed with a constraint restricting estimates to a maximum of zero. Restriction was employed as a means of dealing with inconsistencies by limiting estimates to zero. Among the models assessed, Model 7 was chosen as a candidate for further comparison of its predictive performance with the candidate OLS models as it demonstrated the lowest error terms as shown by Akaike Information Criterion and Bayesian Information Criterion.

The modelling of VAS values assessed five OLS models and three GLMs (Table 1). The OLS regression showed the main effects (Model 1) and adding the variables N2-N5 (Model 2). Levels 4 and 5 for the mobility were combined to address the inconsistency (Model 3). The variables N2-N5 were added to the main effects (Model 4) and N2-N4 included (Model 5). Similar to the case of TTO, VAS Models 3 and 5, which fulfilled the requirement of monotonicity, were again both chosen as candidates for further testing of their predictive performance.

The GLMs, for VAS modelling included the main effects (Model 6), the variables N2-N5 added (Model 7), and the main effects and only N5 (Model 8). Among the models assessed, Model 7 was chosen as a candidate for further testing of its predictive performance because of its lowest error terms according to akaike information criterion and akaike information criterion values. 


\subsection{Predictive Performance of Candidate Models}

Among the TTO and VAS models, Models 3, 5 and 7 were selected as candidate models for their predictive performance based on their better model fit and monotonicity of their estimates, i.e. the models were not specified a priori. To compare the goodness of fit of these three models, the observed (TTO and VAS) values were compared with the predicted (through the models) values by calculating the root mean square error (RMSE), mean absolute error (MAE) and Spearman's correlation coefficients [24-26]. The RMSE has higher values than the MAE and gives higher weights for larger errors as the errors are squared before they are averaged [26]. The final choice of model specification (Model 5 for both TTO and VAS) to be employed for calculation of the TTO and VAS value sets were chosen considering the criteria of consistency (monotonicity), predictive performance (goodness of fit); simplicity of the model (parsimony) and ease of understanding by non-experts in statistics (transparency).

\subsection{Model Validation}

The final models were assessed for their robustness through split sample validation and simple bootstrap analysis (Tables S2-7 of the ESM1). In the split sample validation, the total samples were randomly divided into two groups of equal size (6691 and 6690 for TTO models; 11,950 and 11,949 for VAS models), and the estimations from one half were employed to predict the values in the remaining half, respectively for the TTO and VAS samples. In the simple bootstrap analysis, resampling with replacement was used, 1000 for the TTO sample and 100 for the larger VAS sample. Determining the size of the resample considered original sample size, which was larger for VAS than for TTO. The final models were tested on the resamples to assess model performance.

\subsection{Sensitivity Analyses}

An inverse probability weighting approach was followed for the weighting procedure applied to control for selection bias (Tables S8-10 and Figs. S3-4 of the ESM) [27]. The influence of sociodemographic variables was assessed by adding them to the final models sequentially (Tables S11 [TTO] and S12 [VAS] of the ESM). All the analyses were conducted using SAS software version 9.4 (SAS Institute Inc., Cary, NC, USA).

\section{Results}

Sociodemographic characteristics and self-reported health status of the respondents are shown in Table 2. The distribution of educational level was similar to that in census data (Table S1 of the ESM). A total of 896 health states ( $28.7 \%$ of the 3125 possible EQ-5D-5L health states) were reported by the 25,867 respondents. For the TTO and VAS value sets development, the respective samples provided 531 and 831 health states, respectively (Table S13 of the ESM shows the characteristics of the sample presented with the TTO question.)

\subsection{EQ-5D-5L Value Set Developed by Time Trade-Off Valuation}

Based on OLS (Table 3), the main effect Model 1 showed monotonic decrement in the TTO value corresponding to an increase in the level of severity in each dimension with the exception of moving from severity level 4 to 5 in the mobility, self-care and usual activities dimensions. Models 2 and 4 showed inconsistency in at least one of the coefficients. In contrast, Model 3 (containing a combination of levels 4 and 5 for the dimensions of mobility, self-care and usual activities) and Model 5 (a combination of levels 4 and 5 for the dimensions of mobility, self-care and usual activities together with the N5 variable) showed consistency in all coefficients.

Based on constraint GLMs (Table 4), the main effect Model 6, Model 7 including all $\mathrm{N}$ variables, and Models 8 and 9 with selected $\mathrm{N}$ variables were developed. Among these, Model 7 showed the lowest prediction error indicating a better model fit.

Results of the comparison of the candidate models showed that the MAE and RMSE coefficients, indicating level of predictive performance, for Models 3 and 5 were equal and also better than for Model 7 (Table 5). However, Model 5 had an N5 variable that differentiated between levels 4 and 5 with the added decrement attached. Based on the goodness-of-fit analyses, together with the consistency criteria and the fact that the N5 variable was significant, Model 5 was chosen as the final model for estimation of an experience-based TTO value set. The predictions for the TTO values showed a pronounced deviation from the observed values at worse health states. The findings of split sample validation and simple bootstrap analysis indicated that the final TTO model, along with the other candidate models, was stable (Tables S2-S4 of the ESM). A graph comparing the observed with predicted TTO values based on the final model (Model 5) is shown in Fig. 1.

\subsection{EQ-5D-5L Value Set Developed by Visual Analogue Scale Valuation}

Based on OLS (Table 6), the main effect Model 1 showed monotonic decrements from mild to more severe levels in each dimension, with the exception of the move from level 4 to 5 in the mobility dimension. In Model 2 (added terms 
Table 2 Characteristics of respondents in Life \& Health $2017(n=25,867)$

\begin{tabular}{|c|c|c|}
\hline Variable & $\%$ & $n$ \\
\hline \multicolumn{3}{|l|}{ Sex } \\
\hline Men & 47.4 & 12,249 \\
\hline Women & 52.6 & 13,618 \\
\hline Mean age (years) [SD] & 64.3 & \\
\hline \multicolumn{3}{|l|}{ Age group (years) } \\
\hline $30-34$ & 4.4 & 1127 \\
\hline $35-39$ & 4.6 & 1202 \\
\hline $40-44$ & 5.7 & 1473 \\
\hline $45-49$ & 6.7 & 1722 \\
\hline $50-54$ & 7.0 & 1824 \\
\hline $55-59$ & 7.4 & 1917 \\
\hline $60-64$ & 8.3 & 2144 \\
\hline $65-69$ & 10.2 & 2647 \\
\hline $70-74$ & 17.4 & 4489 \\
\hline $75-79$ & 11.5 & 2972 \\
\hline $80-84$ & 6.7 & 1723 \\
\hline $85-89$ & 6.8 & 1762 \\
\hline $90-94$ & 2.7 & 703 \\
\hline $95+$ & 0.6 & 162 \\
\hline \multicolumn{3}{|l|}{ Educational level } \\
\hline Low & 23.2 & 6005 \\
\hline Medium & 42.6 & 11,027 \\
\hline High & 33.6 & 8694 \\
\hline Missing & 0.6 & 141 \\
\hline \multicolumn{3}{|l|}{ Income } \\
\hline First quintile & 19.9 & 5159 \\
\hline Second quintile & 20.0 & 5160 \\
\hline Third quintile & 19.9 & 5159 \\
\hline Fourth quintile & 20.0 & 5160 \\
\hline Fifth quintile & 19.9 & 5159 \\
\hline Missing & 0.3 & 70 \\
\hline \multicolumn{3}{|l|}{ Self-rated health } \\
\hline Very good & 15.7 & 4064 \\
\hline Good & 48.9 & 12,650 \\
\hline Neither good nor bad & 28.5 & 7378 \\
\hline Bad & 5.1 & 1323 \\
\hline Very bad & 1.0 & 262 \\
\hline Missing & 0.7 & 190 \\
\hline Less than good self-rated health & 34.6 & 9153 \\
\hline \multicolumn{3}{|l|}{ Mobility } \\
\hline No problems & 67.6 & 17,491 \\
\hline Slight problems & 17.2 & 4448 \\
\hline Moderate problems & 9.7 & 2500 \\
\hline Severe problems & 4.4 & 1127 \\
\hline Extreme problems & 1.2 & 301 \\
\hline \multicolumn{3}{|l|}{ Self-care } \\
\hline No problems & 89.2 & 23,076 \\
\hline Slight problems & 6.0 & 1553 \\
\hline Moderate problems & 2.8 & 721 \\
\hline Severe problems & 1.1 & 296 \\
\hline Extreme problems & 0.8 & 221 \\
\hline
\end{tabular}


Table 2 (continued)

\begin{tabular}{|c|c|c|}
\hline Variable & $\%$ & $n$ \\
\hline \multicolumn{3}{|l|}{ Usual activities } \\
\hline No problems & 69.2 & 17,900 \\
\hline Slight problems & 18.2 & 4701 \\
\hline Moderate problems & 7.1 & 1834 \\
\hline Severe problems & 3.6 & 926 \\
\hline Extreme problems & 2.0 & 506 \\
\hline \multicolumn{3}{|l|}{ Pain/discomfort } \\
\hline No problems & 32.0 & 8264 \\
\hline Slight problems & 39.8 & 10,308 \\
\hline Moderate problems & 22.5 & 5828 \\
\hline Severe problems & 5.2 & 1352 \\
\hline Extreme problems & 0.4 & 115 \\
\hline \multicolumn{3}{|l|}{ Anxiety/depression } \\
\hline No problems & 62.8 & 16,249 \\
\hline Slight problems & 28.8 & 7453 \\
\hline Moderate problems & 6.0 & 1548 \\
\hline Severe problems & 2.0 & 510 \\
\hline Extreme problems & 0.4 & 107 \\
\hline Problem in at least one EQ-5D-5L dimension & 75.9 & 19,633 \\
\hline Problem at level 5 in at least one EQ-5D-5L dimension & 2.9 & 759 \\
\hline Mean EQ VAS score [SD] & $76.1[18.7]$ & \\
\hline Mean TTO value $[\mathrm{SD}](n=13,381)$ & $0.9[0.2]$ & \\
\hline
\end{tabular}

$S D$ standard deviation, $S R H$ self-rated health, TTO time trade-off, VAS visual analogue scale

N2-N5), consistency decrements were shown with exceptions in the decrement from level 4 to 5 of the mobility dimension and the $\mathrm{N} 5$ term. Model 3 (mobility levels 4 and 5 combined) and Model 5 (mobility levels 4 and 5 combined and N2-N4 added) showed consistent decrements for all variables and were taken as candidate models to be assessed for their model performances. Model 4, which included combined levels 4 and 5 in the mobility dimension and the $\mathrm{N}$ variables showed inconsistency in the $\mathrm{N} 5$ variable. Of the three constraint GLMs (Table 7), Model 7, which added the $\mathrm{N}$ variables to the five EQ-5D-5L dimensions, showed a better model fit based on the lowest prediction error, hence making it one of the candidate models.

Model 5 demonstrated the best fit with the lowest MAE and RMSE as well as the highest correlation between observed and predicted VAS values (Table 6). As it fulfilled the criteria for model selection, Model 5 was chosen as the final model to be proposed to be employed for estimation of the VAS value set. Although the econometric strategy was the same for estimation of the TTO and VAS value sets, they resulted in partly different model specifications. The findings of split sample validation and simple bootstrap analyses demonstrated stability of all the candidate VAS models (Tables S5-7 of the ESM1). A graph comparing the observed with predicted VAS values based on the final model (Model 5) is shown in Fig. 2.

\subsection{Impact of Health Dimensions and Severity Levels on Time Trade-Off and Visual Analogue Scale Values}

The final TTO and VAS models, with coefficients for direct calculation of the experience-based TTO and VAS value sets, are presented in Table 8 together with examples demonstrating how to calculate EQ-5D-5L TTO and VAS values for a health state.

In the final TTO model, the anxiety/depression dimension had the greatest effect on TTO values $(0.234$ for level 5; 0.200 for level 4), followed by pain/discomfort ( 0.197 for level 5) and usual activities (0.164 for levels 4 and 5) (Table 8). The coefficient for level 3 was greatest in absolute terms for the usual activities dimension (0.114). The coefficient for level 2 was smallest for the pain/discomfort dimension (0.011), followed by self-care (0.025) and mobility (0.029). The smallest coefficient for level 5 was seen for mobility (0.052).

A similar pattern was found in the final VAS model with anxiety/depression having the greatest effect on VAS values (27.3 for level 5), followed by pain/discomfort and usual activities (17.1 for levels 5) (Table 8). The coefficients for levels 4 and 3 were greatest for anxiety/depression (16.5 and 10.8, respectively). Pain/discomfort had the smallest coefficient for level 2 (1.6) followed by self-care (2.3) and 


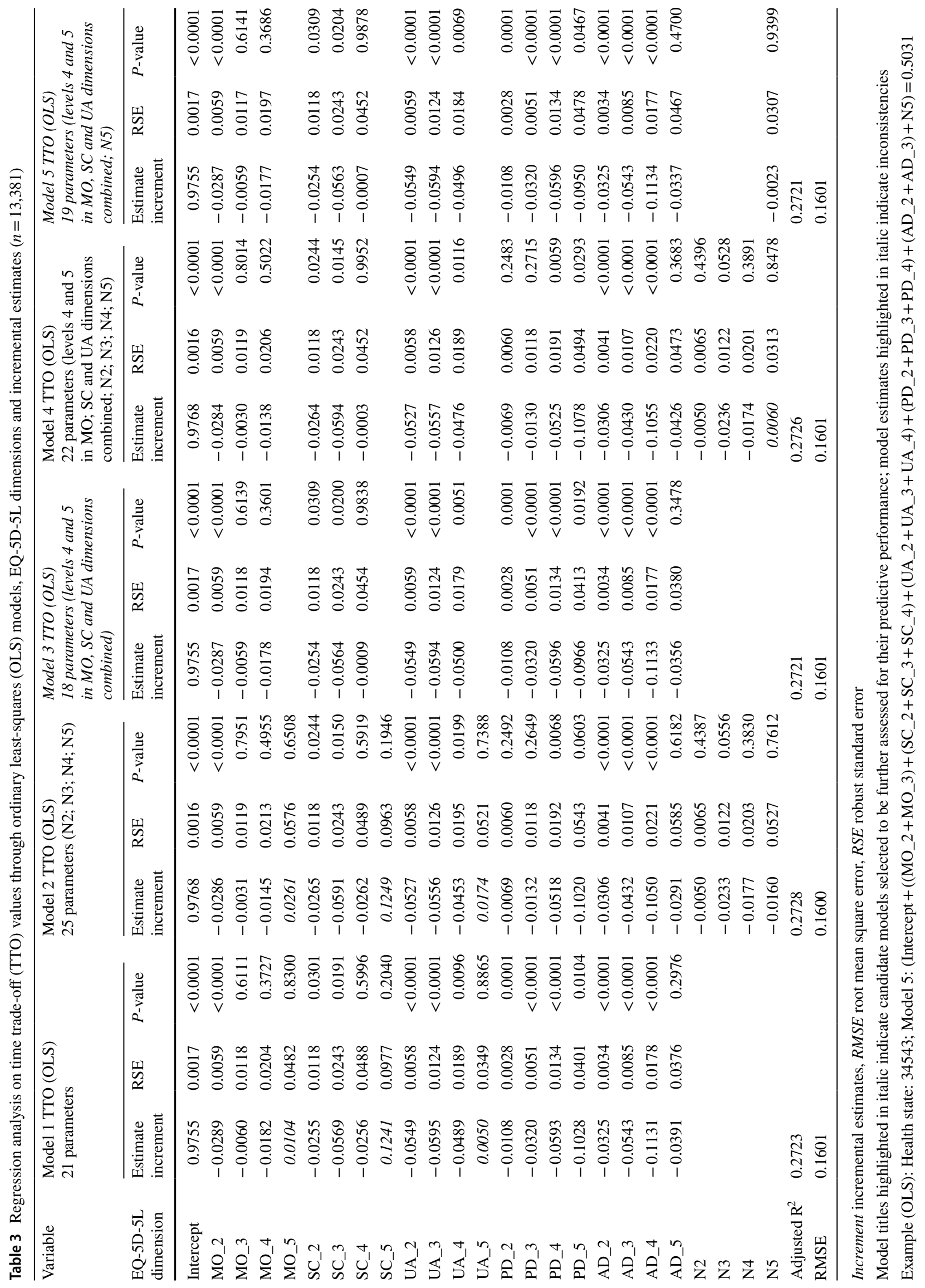




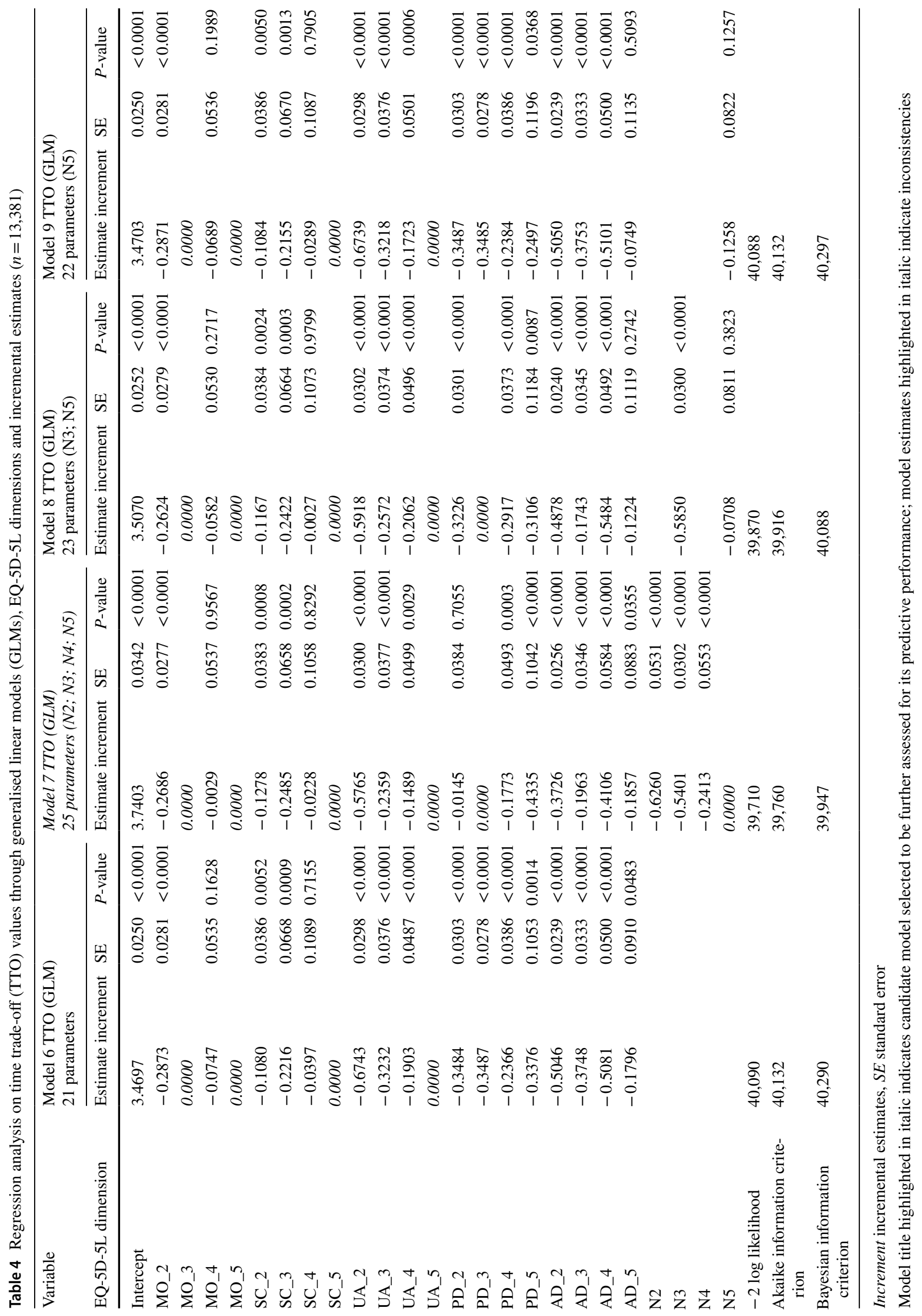


Table 5 Predictive performances (mean absolute error [MAE], root mean square error [RMSE], correlation) of the candidate models developed through regression on time trade-off (TTO) and visual analogue scale (VAS) values

\begin{tabular}{|c|c|c|c|c|c|c|c|c|c|c|c|}
\hline \multirow{2}{*}{$\begin{array}{l}\text { Number of } \\
\text { health states } \\
\text { observed }\end{array}$} & \multirow{2}{*}{$\begin{array}{l}\text { Number of health } \\
\text { states in the } \\
\text { sample }\end{array}$} & \multirow[t]{2}{*}{ Sample size } & \multicolumn{3}{|c|}{ Model 3 TTO (OLS) } & \multicolumn{3}{|c|}{ Model 5 TTO (OLS) } & \multicolumn{3}{|c|}{ Model 7 TTO (GLM) } \\
\hline & & & MAE & RMSE & Correlation & MAE & RMSE & Correlation & MAE & RMSE & Correlation \\
\hline All & 531 & 13,381 & 0.0938 & 0.1600 & 0.4647 & 0.0938 & 0.1600 & 0.4647 & 0.0940 & 0.1601 & 0.4634 \\
\hline$\geq 5$ & 138 & 12,714 & 0.0878 & 0.1530 & 0.4154 & 0.0878 & 0.1530 & 0.4154 & 0.0880 & 0.1531 & 0.4139 \\
\hline \multirow[t]{3}{*}{$\geq 10$} & 77 & 12,329 & 0.0843 & 0.1491 & 0.3828 & 0.0843 & 0.1491 & 0.3828 & 0.0846 & 0.1493 & 0.3811 \\
\hline & & & \multicolumn{3}{|c|}{ Model 3 VAS (OLS) } & \multicolumn{3}{|c|}{ Model 5 VAS (OLS) } & \multicolumn{3}{|c|}{ Model 7 VAS (GLM) } \\
\hline & & & MAE & RMSE & Correlation & MAE & RMSE & Correlation & MAE & RMSE & Correlation \\
\hline All & 831 & 23,899 & 0.0929 & 0.1255 & 0.6876 & 0.0922 & 0.1250 & 0.6880 & 0.0923 & 0.1252 & 0.6873 \\
\hline$\geq 5$ & 279 & 22,939 & 0.0910 & 0.1229 & 0.6641 & 0.0903 & 0.1224 & 0.6646 & 0.0904 & 0.1226 & 0.6638 \\
\hline$\geq 10$ & 163 & 22,201 & 0.0898 & 0.1211 & 0.6424 & 0.0892 & 0.1207 & 0.6429 & 0.0893 & 0.1209 & 0.6420 \\
\hline
\end{tabular}

GLM generalised linear model, $O L S$ ordinary least squares

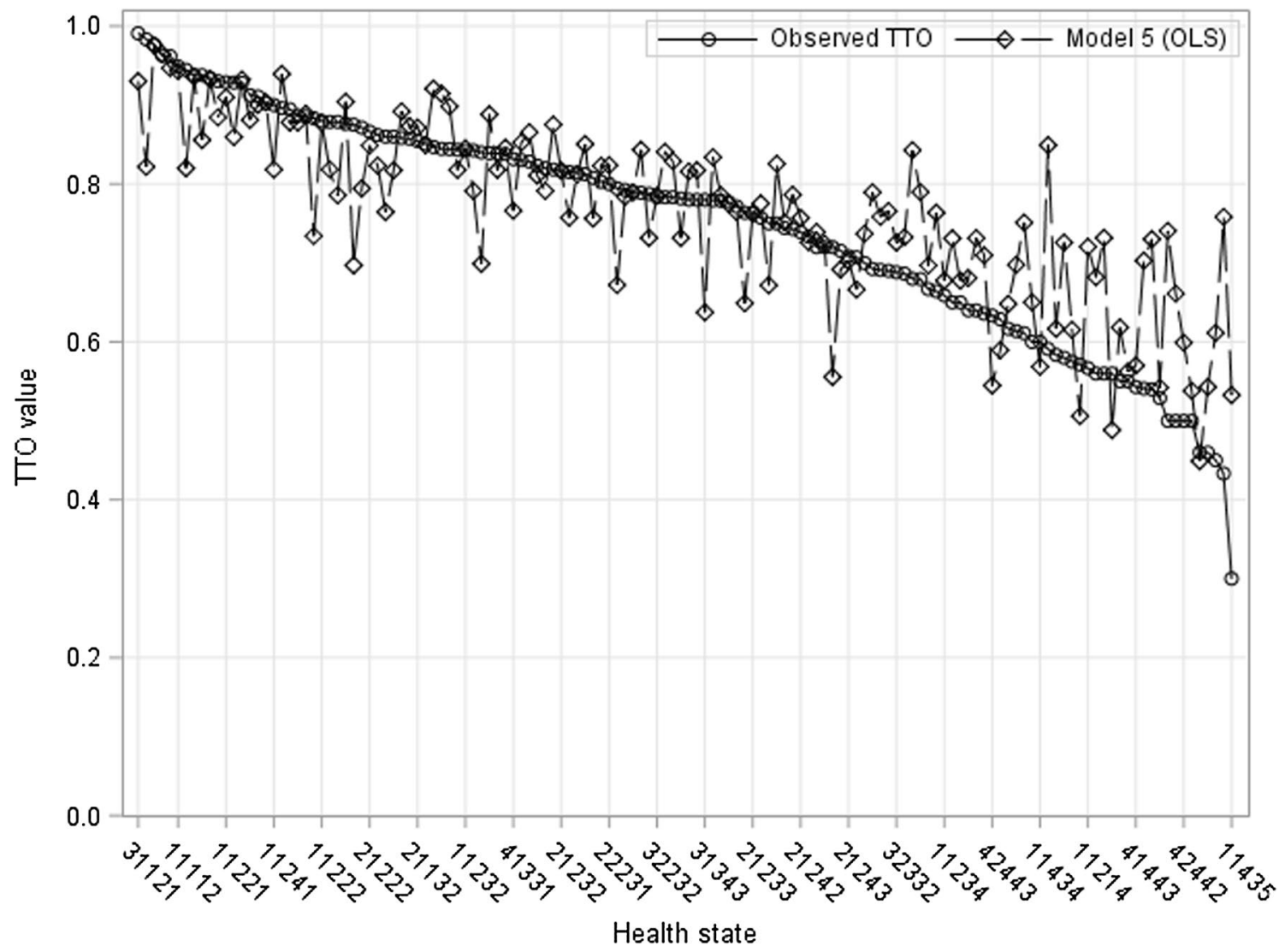

Fig. 1 Line plot of mean predicted time trade-off (TTO) values based on the final model compared to mean observed TTO values for health states with five or more observations (sorted by observed TTO value). OLS ordinary least squares

mobility (3.4). For level 5, the smallest coefficients were seen for self-care (7.8) and mobility (9.1).

The predicted TTO and VAS values for all 3125 health states are presented in Fig. 3. A Swedish TTO value set for EQ-5D-5L and a Swedish VAS value set for EQ-5D-5L are presented in the ESM2 annd ESM3, respectively.

\subsection{Results of Additional Analyses}

The distributions of the health states in the TTO and VAS samples according to the Misery Index are presented in Fig. S5-6 of the ESM1. Figures S7-8 of the ESM1 show the distribution of TTO and VAS values, and Tables S14-23 of 


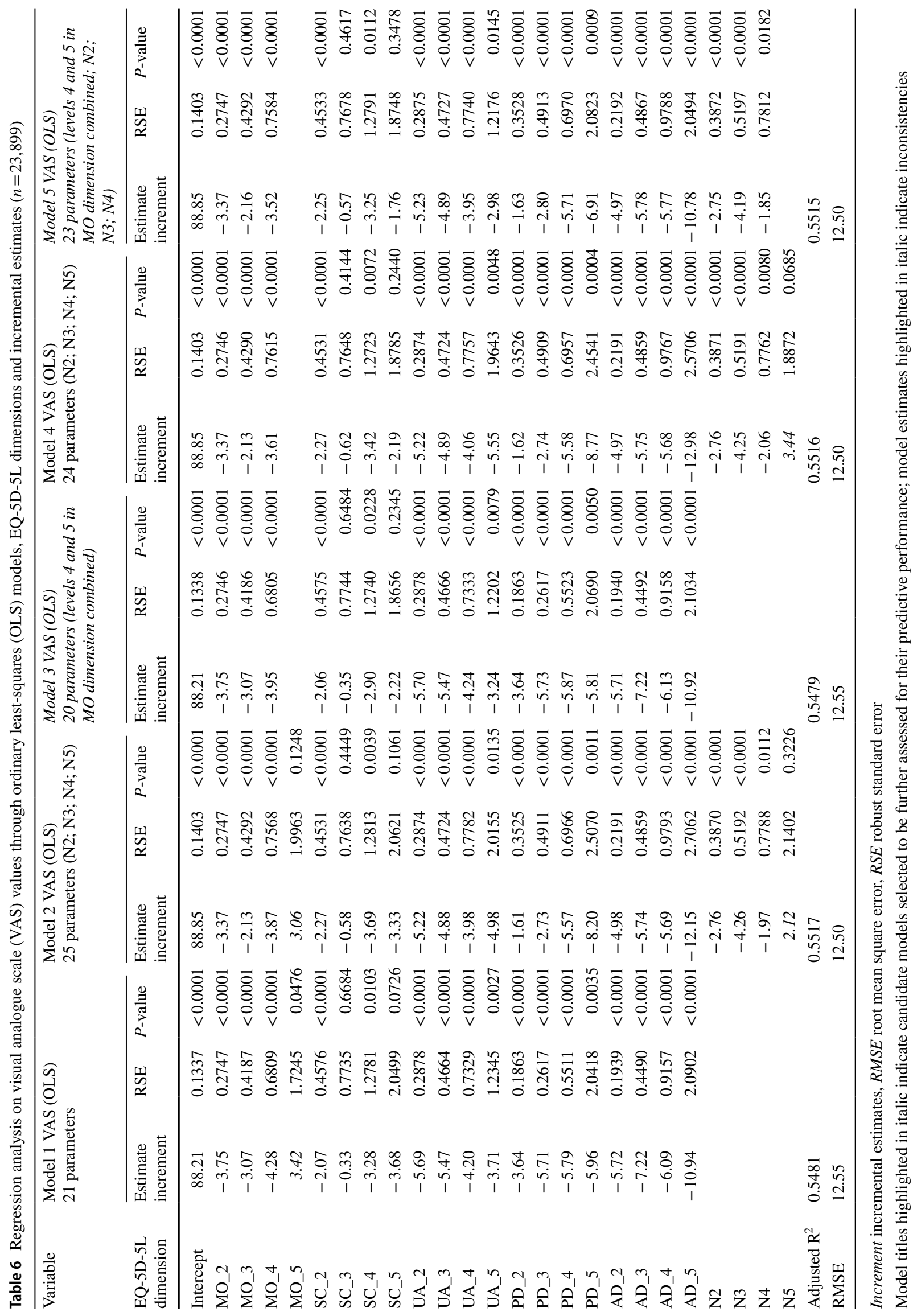


Table 7 Regression analysis on visual analogue scale (VAS) values through generalised linear models (GLMs), EQ-5D-5L dimensions and incremental estimates $(n=23,899)$

\begin{tabular}{|c|c|c|c|c|c|c|c|c|c|}
\hline \multirow{2}{*}{$\begin{array}{l}\text { Variable } \\
\text { EQ-5D-5L dimension }\end{array}$} & \multicolumn{3}{|l|}{$\begin{array}{l}\text { Model } 6 \text { VAS (GLM) } \\
21 \text { parameters }\end{array}$} & \multicolumn{3}{|c|}{$\begin{array}{l}\text { Model } 7 \text { VAS }(G L M) \\
25 \text { parameters }(N 2 ; N 3 ; N 4 ; N 5)\end{array}$} & \multicolumn{3}{|l|}{$\begin{array}{l}\text { Model } 8 \text { VAS (GLM) } \\
22 \text { parameters (N5) }\end{array}$} \\
\hline & Estimate increment & SE & $P$-value & Estimate increment & SE & $P$-value & Estimate increment & SE & $P$-value \\
\hline Intercept & 1.9640 & 0.0034 & $<0.0001$ & 2.0759 & 0.0042 & $<0.0001$ & 1.9640 & 0.0034 & $<0.0001$ \\
\hline MO_2 & -0.2205 & 0.0048 & $<0.0001$ & -0.1865 & 0.0048 & $<0.0001$ & -0.2205 & 0.0048 & $<0.0001$ \\
\hline MO_3 & -0.1280 & 0.0062 & $<0.0001$ & -0.0719 & 0.0063 & $<0.0001$ & -0.1280 & 0.0062 & $<0.0001$ \\
\hline MO_4 & -0.1641 & 0.0087 & $<0.0001$ & -0.1555 & 0.0096 & $<0.0001$ & -0.1641 & 0.0087 & $<0.0001$ \\
\hline MO_5 & 0.0000 & & & 0.0000 & & & 0.0000 & & \\
\hline SC_2 & -0.0724 & 0.0066 & $<0.0001$ & -0.0900 & 0.0066 & $<0.0001$ & -0.0724 & 0.0066 & $<0.0001$ \\
\hline SC_3 & -0.0114 & 0.0104 & 0.2754 & -0.0218 & 0.0104 & 0.0353 & -0.0114 & 0.0104 & 0.2754 \\
\hline SC_4 & -0.1253 & 0.0164 & $<0.0001$ & -0.1426 & 0.0162 & $<0.0001$ & -0.1253 & 0.0164 & $<0.0001$ \\
\hline SC_5 & -0.1178 & 0.0217 & $<0.0001$ & -0.0834 & 0.0215 & 0.0001 & -0.1178 & 0.0217 & $<0.0001$ \\
\hline UA_2 & -0.3222 & 0.0049 & $<0.0001$ & -0.2805 & 0.0049 & $<0.0001$ & -0.3222 & 0.0049 & $<0.0001$ \\
\hline UA_3 & -0.2204 & 0.0066 & $<0.0001$ & -0.1859 & 0.0067 & $<0.0001$ & -0.2204 & 0.0066 & $<0.0001$ \\
\hline UA_4 & -0.1591 & 0.0097 & $<0.0001$ & -0.1563 & 0.0102 & $<0.0001$ & -0.1591 & 0.0097 & $<0.0001$ \\
\hline UA_5 & -0.1598 & 0.0142 & $<0.0001$ & -0.1365 & 0.0140 & $<0.0001$ & -0.1598 & 0.0142 & $<0.0001$ \\
\hline PD_2 & -0.2949 & 0.0044 & $<0.0001$ & -0.0688 & 0.0064 & $<0.0001$ & -0.2949 & 0.0043 & $<0.0001$ \\
\hline PD_3 & -0.2927 & 0.0044 & $<0.0001$ & -0.1059 & 0.0067 & $<0.0001$ & -0.2927 & 0.0044 & $<0.0001$ \\
\hline PD_4 & -0.2266 & 0.0071 & $<0.0001$ & -0.2469 & 0.0090 & $<0.0001$ & -0.2266 & 0.0071 & $<0.0001$ \\
\hline PD_5 & -0.3214 & 0.0255 & $<0.0001$ & -0.3728 & 0.0255 & $<0.0001$ & -0.3214 & 0.0255 & $<0.0001$ \\
\hline AD_2 & -0.3395 & 0.0036 & $<0.0001$ & -0.2686 & 0.0039 & $<0.0001$ & -0.3395 & 0.0036 & $<0.0001$ \\
\hline AD_3 & -0.3204 & 0.0064 & $<0.0001$ & -0.2288 & 0.0068 & $<0.0001$ & -0.3204 & 0.0064 & $<0.0001$ \\
\hline AD_4 & -0.2565 & 0.0116 & $<0.0001$ & -0.2535 & 0.0126 & $<0.0001$ & -0.2565 & 0.0116 & $<0.0001$ \\
\hline AD_5 & -0.5843 & 0.0267 & $<0.0001$ & -0.5445 & 0.0262 & $<0.0001$ & -0.5843 & 0.0267 & $<0.0001$ \\
\hline $\mathrm{N} 2$ & & & & -0.3530 & 0.0078 & $<0.0001$ & & & \\
\hline N3 & & & & -0.2960 & 0.0074 & $<0.0001$ & & & \\
\hline N4 & & & & -0.0632 & 0.0100 & $<0.0001$ & & & \\
\hline N5 & & & & 0.0000 & & & 0.0000 & & \\
\hline-2 log likelihood & 336,000 & & & 331,577 & & & 336,000 & & \\
\hline $\begin{array}{l}\text { Akaike information } \\
\text { criterion }\end{array}$ & 336,042 & & & 331,627 & & & 336,044 & & \\
\hline $\begin{array}{l}\text { Bayesian information } \\
\text { criterion }\end{array}$ & 336,212 & & & 331,829 & & & 336,222 & & \\
\hline
\end{tabular}

Increment incremental estimates, RMSE root mean square error, $S E$ standard error

Model title highlighted in italic indicates candidate model selected to be further assessed for its predictive performance; model estimates highlighted in italic indicate inconsistencies

the ESM1 show the analyses of characteristics of respondents with $\mathrm{TTO}=0$ and $\mathrm{TTO}=1, \mathrm{VAS}=0$ and $\mathrm{VAS}=100$, and a health state of 11111 . Results of the sensitivity analysis using the weighting approach for selection bias showed stable coefficients (Tables S8-10 and Figs. S3-S4 of the ESM1) and modest influence of sociodemographic variables (Tables S11-12 of the ESM1).

\section{Discussion}

\subsection{Summary of Findings}

This study aimed at generating value sets for all health states experienced in a general population. We have estimated EQ5D-5L value sets for Sweden based on TTO and VAS using 


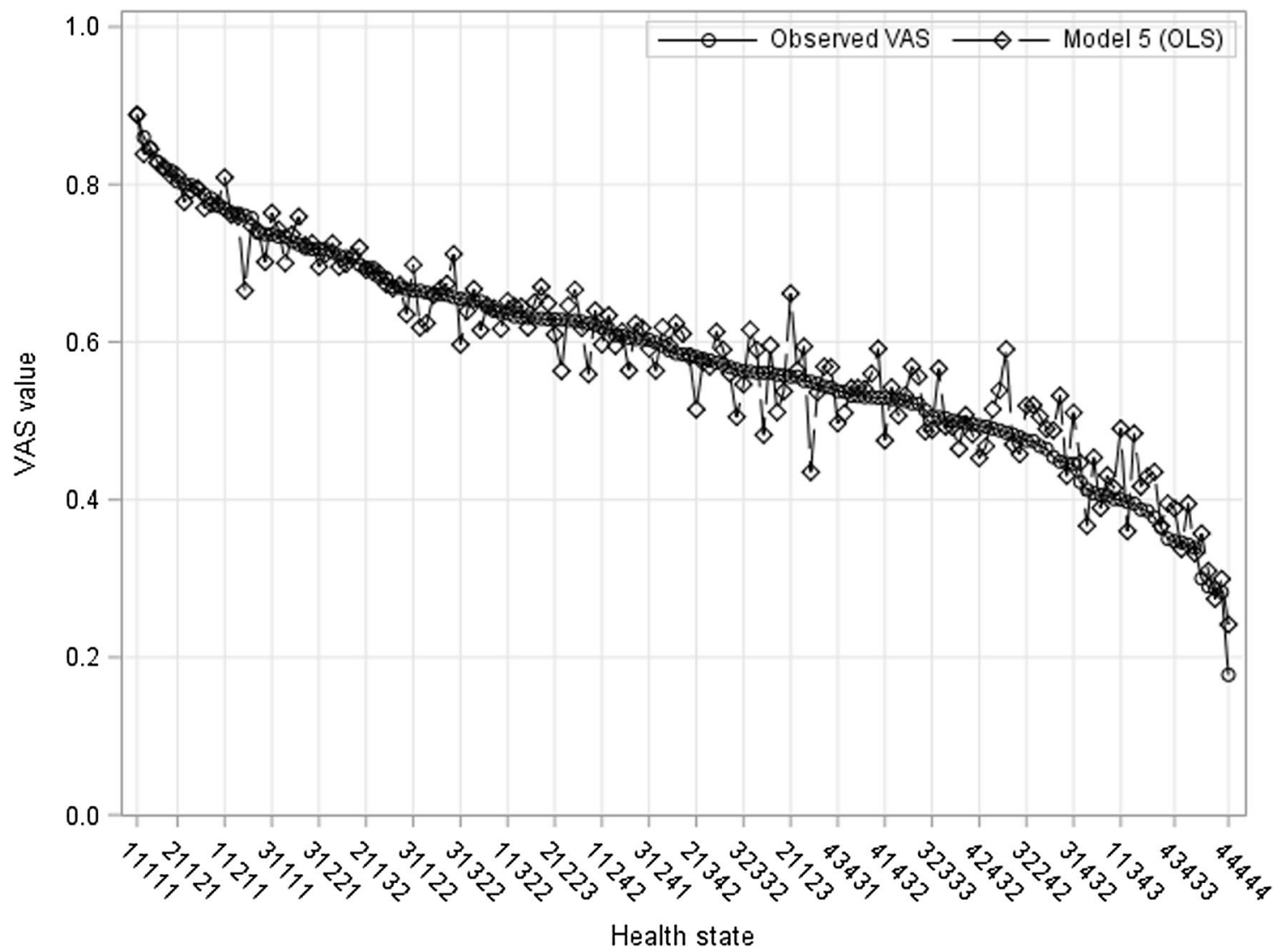

Fig. 2 Line plot of mean predicted visual analogue scale (VAS) values based on the final model compared to mean observed VAS values for health states with five or more observations (sorted by observed VAS value). OLS ordinary least squares

data from a cross-sectional population-based health survey. The 25,867 respondents reported valuations of their currently experienced health state of a total of 896 health states, or nearly $29 \%$ of all states of the EQ-5D-5L, meaning that our results are derived from a large data set with relatively good coverage of possible health states. Our sample does not cover all regions in Sweden, but the sociodemographic composition of the CDUST Region suggests that the results can be generalisable to Sweden as a whole with respect to the studied age groups. Furthermore, conduct of a written survey precluded use of an iterative procedure in TTO elicitation, making study results comparable to other studies using direct TTO valuation.

Our preferred regression models used OLS estimation for both TTO and VAS values and showed consistency in all coefficients. In the preferred TTO regression model, levels 4 and 5 for the dimensions of mobility, self-care and usual activities were combined, which means we could not distinguish between the two worst severity levels in those dimensions. Including the interaction variable N5, which indicates severity level 5 in at least one of the five dimensions, made it possible to distinguish between the two worst severity levels where no other dimension is at level 5 as this coefficient is applied only once. In the preferred VAS regression model, levels 4 and 5 of the mobility dimension were combined. The interaction variables N2-N4 were included, indicating that each of these terms reflects a statistically significant decrement in VAS value if any of the dimensions is at severity level 2, 3 or 4, respectively. The frequency distribution of health states in the population sample used, together with the respective model accuracy linked to these states, will also determine model choice.

The relative impact of the different dimensions on TTO and VAS was similar, with anxiety/depression having the greatest effect (the greatest coefficient in absolute terms), followed by pain/discomfort and usual activities. For level 5 , the smallest coefficient was observed for the mobility and self-care dimension in the TTO and VAS models, respectively.

\subsection{Econometric Considerations}

Our main challenge was to develop an appropriate econometric model that can predict TTO and VAS values for different combinations of EQ-5D-5L dimensions and levels in a consistent manner. A number of caveats have been raised 
Table 8 Calculation of time trade-off (TTO) and visual analogue scale (VAS) values based on TTO $(n=13,381)$ and VAS $(n=23,889)$ models

\begin{tabular}{|c|c|c|}
\hline EQ-5D-5L dimension & $\begin{array}{l}\text { Model } 5 \text { TTO } \\
\text { (OLS) }\end{array}$ & Health state (34543) \\
\hline Intercept & 0.9755 & 0.9755 \\
\hline \multicolumn{3}{|l|}{ Mobility } \\
\hline Level 2 & -0.0287 & \\
\hline Level 3 & -0.0346 & -0.0346 \\
\hline Level 4 or 5 & -0.0523 & \\
\hline \multicolumn{3}{|l|}{ Self-care } \\
\hline Level 2 & -0.0254 & \\
\hline Level 3 & -0.0817 & \\
\hline Level 4 or 5 & -0.0824 & -0.0824 \\
\hline \multicolumn{3}{|l|}{ Usual activities } \\
\hline Level 2 & -0.0549 & \\
\hline Level 3 & -0.1143 & \\
\hline Level 4 or 5 & -0.1639 & -0.1639 \\
\hline \multicolumn{3}{|l|}{ Pain/discomfort } \\
\hline Level 2 & -0.0108 & \\
\hline Level 3 & -0.0428 & \\
\hline Level 4 & -0.1024 & -0.1024 \\
\hline Level 5 & -0.1974 & \\
\hline \multicolumn{3}{|l|}{ Anxiety/depression } \\
\hline Level 2 & -0.0325 & \\
\hline Level 3 & -0.0868 & -0.0868 \\
\hline Level 4 & -0.2002 & \\
\hline Level 5 & -0.2339 & \\
\hline $\begin{array}{l}\text { N5 (at least one dimension } \\
\text { at severity level 5) }\end{array}$ & -0.0023 & -0.0023 \\
\hline TTO value & & 0.5031 \\
\hline
\end{tabular}

Table 8 (continued)

EQ-5D-5L dimension

Model 5 VAS Health state (34543) (OLS)

\begin{tabular}{|c|c|c|}
\hline Intercept & 88.85 & 88.85 \\
\hline \multicolumn{3}{|l|}{ Mobility } \\
\hline Level 2 & -3.37 & \\
\hline Level 3 & -5.53 & -5.53 \\
\hline Level 4 or 5 & -9.05 & \\
\hline \multicolumn{3}{|l|}{ Self-care } \\
\hline Level 2 & -2.25 & \\
\hline Level 3 & -2.82 & \\
\hline Level 4 & -6.07 & -6.07 \\
\hline Level 5 & -7.83 & \\
\hline \multicolumn{3}{|l|}{ Usual activities } \\
\hline Level 2 & -5.23 & \\
\hline Level 3 & -10.12 & \\
\hline Level 4 & -14.07 & \\
\hline Level 5 & -17.05 & -17.05 \\
\hline \multicolumn{3}{|l|}{ Pain/discomfort } \\
\hline Level 2 & -1.63 & \\
\hline Level 3 & -4.43 & \\
\hline Level 4 & -10.14 & -10.14 \\
\hline Level 5 & -17.05 & \\
\hline \multicolumn{3}{|l|}{ Anxiety/depression } \\
\hline Level 2 & -4.97 & \\
\hline Level 3 & -10.75 & -10.75 \\
\hline Level 4 & -16.52 & \\
\hline Level 5 & -27.30 & \\
\hline $\begin{array}{l}\mathrm{N} 2 \text { (at least one dimension } \\
\text { at severity level 2,3,4 } \\
\text { or } 5 \text { ) }\end{array}$ & -2.75 & -2.75 \\
\hline $\begin{array}{l}\mathrm{N} 3 \text { (at least one dimension } \\
\text { at severity level } 3,4, \text { or } 5 \text { ) }\end{array}$ & -4.19 & -4.19 \\
\hline $\begin{array}{l}\text { N4 (at least one dimension } \\
\text { at severity level } 4 \text { or } 5 \text { ) }\end{array}$ & -1.85 & -1.85 \\
\hline VAS value & & 30.52 \\
\hline
\end{tabular}

$O L S$ ordinary least squares 


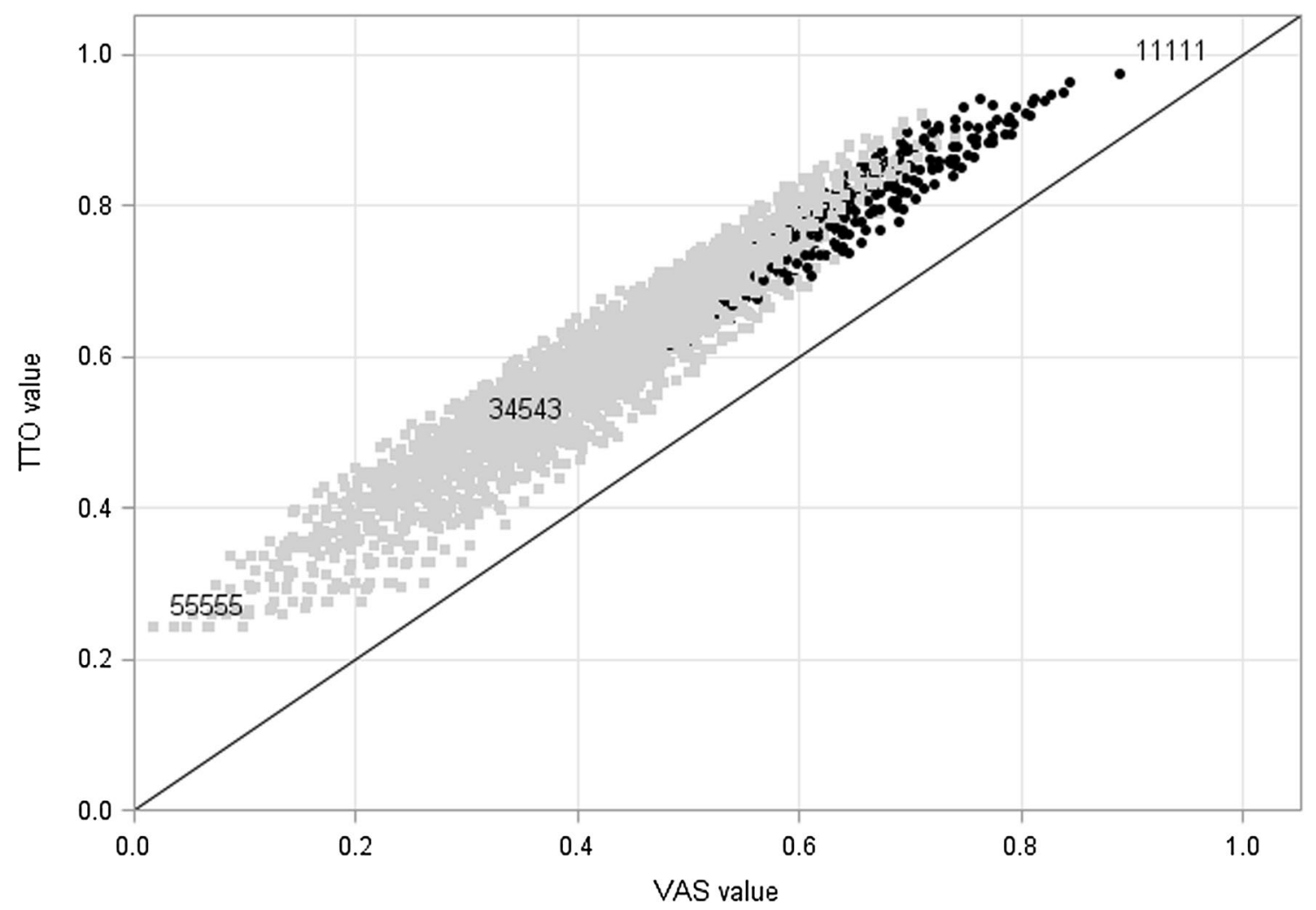

Severity $=$ At least 1 level 4 or 5 - No level 4 or 5

Fig. 3 A scatter plot of predicted visual analogue scale (VAS) and time trade-off (TTO) values based on final models

by Hernández-Alava et al. [7] in relation to similar studies, mainly Devlin et al. [6], although some of these caveats do not arise in our study, e.g. small sample, few health states valued and dependence between values on a within-respondent basis. The large sample of the present study is an obvious strength, as is the good coverage of possible health states. The TTO and VAS value sets are based on valuations of $17 \%$ and $27 \%$ of the possible health states, respectively, a higher percentage compared with studies developing nonexperienced value sets, where $2.8 \%$ of the 3125 possible health states were directly valued [3].

The sensitivity analyses undertaken in general indicate robustness in our results. This is the case also with respect to often observed inconsistencies, which has been documented in the EQ-5D-5L value set for the Netherlands [28], and for the TTO component of the EQ-5D-5L value sets for England [6], Germany [29], Ireland [30] and Spain [31], as well as in the EQ-5D-5L VAS value set for Germany [17]. Our study also reports beyond these inconsistencies that some point estimates of levels are indeed successively higher (greater coefficients in absolute terms) but insignificantly so. Several studies with different estimation models thus encountered such inconsistencies. Besides problems in econometric specification, it cannot be excluded from our study that the population was not able to discriminate between certain levels in the valuation approaches used here. A potential issue is the heterogeneity of effects in subpopulations. The TTO value was relatively constant with age, and for the VAS values there was no clear age gradient. Even if there was a modest influence of socioeconomic variables on TTO and VAS values, further analyses should investigate heterogeneity in subpopulations, especially among men and women as women had significantly higher TTO and VAS values than men. That our samples were restricted to certain age groups (30 years of age and above for VAS, and for TTO, the upper age limit was 69 years) is also a limitation and might be a limitation in terms of generalisability.

\subsection{Results in Context}

Our study adds to the emerging evidence in the literature regarding EQ-5D-5L value sets [3-6] and provides the first such experience-based value set based on TTO. Regarding an experience-based VAS value set for EQ-5D-5L, only one set for Germany exists so far [17]. In comparison, the Swedish study has almost three times as many respondents and, even more importantly, the number of health states observed exceeds that of the German study by a factor of 2.75 . This 
assured a stronger base for deriving a value set. While the German study only used GLMs models because of previous specification tests with EQ-5D-3L data, it was interesting to learn that an OLS model outperformed the GLMs in the present study.

The finding that the anxiety/depression dimension had the greatest impact on both TTO and VAS outcomes was also seen in the Swedish experience-based TTO and VAS values for the EQ-5D-3L [13]. However, for the EQ-5D-3L, severe problems with usual activities and mobility had a greater impact on the TTO model than pain/discomfort, and usual activities in the VAS model. The TTO value for full health (health state 11111) was 0.975 in the present study, close to the 0.969 in the EQ-5D-3L study. The VAS value for full health was 88.9 in both studies. The TTO value was 0.243 and the VAS value was 1.78 for the most severe health state 55555 .

\subsection{Which Value Set?}

\subsubsection{Experience Based vs Hypothetical}

There is an ongoing discussion, and considerable disagreement, on whether to use value sets generated from individuals with experience from the health states or from individuals valuing described health states. The main argument favouring experience-based value sets is that individuals with their own experience from the health states are often considerably better informed about them compared with those who value health states based merely on a description [18, 32-36]. This may be considered an advantage when the EQ-5D is used as an integral part of the monitoring and assessment of healthcare interventions in quality registers, a common feature in Sweden [37]. The main argument favouring value sets based on described health states stresses that they express social values when elicited from the general population [18, 32, 38-40]. There are also arguments on both sides in the debate stressing the opposing positions' difficulties in making the valuations because of the effects of adaptation, focusing effects and distortions due to reference point effects [18, 32, 35, 40-42].

This study used experience-based values from a population survey, hence one may argue that it considers strengths from both sides in the debate by using values based on experience and by being representative of the general population. An additional advantage with the present approach may be that preferences starting from a real-life context are clearly defined while those starting from an unspecified mix of real context and hypothetical imagination are not.

\subsubsection{For Use in Economic Evaluation}

The VAS was anchored between worst and best imaginable health and did not allow for anchoring between 0 (dead) and 1 (full health). The estimated VAS values do not correspond to the $0-1$ scale required for quality-adjusted life-year calculations. If the presented value sets are to be used in evaluations where it is considered appropriate that the health state 11111 is anchored at 1 , rescaling can be performed.

With or without rescaling, the value sets based on VAS and TTO may yield different health outcomes in practical evaluations. Furthermore, experience-based and hypothetical value sets may also provide differences in estimated health outcomes. Recently, it was shown that the difference between experience-based and hypothetical valuations may be small only for less severe health states [17, 43]. Future studies may shed light on the differences between experience-based and hypothetical valuations, in particular when TTO has been used in the valuation.

\section{Conclusions}

This article reports TTO and VAS value sets for the EQ$5 \mathrm{D}-5 \mathrm{~L}$ for Sweden. The TTO value set is the first such value set based on experience-based TTO valuation. The anxiety/ depression dimension had the greatest impact on both TTO and VAS values. For decision makers with a preference for experienced-based valuations of health states using a representative population-based sample, the reported value sets may be considered fit for purpose to support resource allocation decisions as well as evaluating population health and healthcare performance.

Acknowledgements Open access funding provided by Karolinska Institutet. The authors thank the CDUST Regions for collecting and providing data. We are also grateful for valuable comments and constructive suggestions by two anonymous reviewers.

Authors Contributions The study was conceived by KB. All authors contributed to the design. Preliminary analyses were carried out by $\mathrm{KB}$ and FST, with contributions by U-GG, RL and MH. All authors interpreted the data. KB and FST drafted the first version of the work and all authors revised it critically for important intellectual content. All authors approved the final submitted version of the manuscript, and therefore share collective responsibility and accountability for the manuscript. $\mathrm{KB}$ acts as the overall guarantor.

Funding No specific funding was received for this study. The views expressed by the authors in the publication do not necessarily reflect the views of the EuroQol Group.

Data Availability Data sharing is not possible according to Swedish law. 


\section{Compliance with Ethical Standards}

Conflict of Interest Kristina Burström is a member of the EuroQol Group. Fitsum Sebsibe Teni, Ulf-G Gerdtham, Gert Helgesson, Ola Rolfson and Martin Henriksson have no conflicts of interest that are directly relevant to the content of this article. Reiner Leidl is a member of the EuroQol Group.

Ethics Approval All procedures performed in studies involving human participants were in accordance with the ethical standards of the institutional and/or national research committee (Regional Ethical Review Board in Uppsala (Dnr: 2015/417) and Swedish Ethical Review Authority (Dnr: 2019-00763)) and with the 1964 Helsinki Declaration and its later amendments or comparable ethical standards.

Consent to Participate The pseudonymised data are based on information from individuals who agreed to participate after having been informed about the study. The individuals in the sample were informed that the responded questionnaire would be linked to the Swedish official registries through the personal identification numbers, to obtain register information on a sociodemographic level. The respondents thus accepted the linking of registry data by informed consent. All handling of personal identification numbers was carried out by Statistics Sweden, the statistical administrative authority in Sweden. The survey has been approved by the Regional Ethical Review Board in Uppsala (Dnr: 2015/417). The present study has been approved by the Swedish Ethical Review Authority (Dnr: 2019-00763).

Open Access This article is licensed under a Creative Commons Attribution-NonCommercial 4.0 International License, which permits any non-commercial use, sharing, adaptation, distribution and reproduction in any medium or format, as long as you give appropriate credit to the original author(s) and the source, provide a link to the Creative Commons licence, and indicate if changes were made. The images or other third party material in this article are included in the article's Creative Commons licence, unless indicated otherwise in a credit line to the material. If material is not included in the article's Creative Commons licence and your intended use is not permitted by statutory regulation or exceeds the permitted use, you will need to obtain permission directly from the copyright holder.To view a copy of this licence, visit http://creativecommons.org/licenses/by-nc/4.0/.

\section{References}

1. Rabin R, de Charro F. EQ-5D: a measure of health status from the EuroQol group. Ann Med. 2001;33(5):337-43.

2. Herdman M, Gudex C, Lloyd A, Janssen M, Kind P, Parkin D. Development and preliminary testing of the new five-level version of EQ-5D (EQ-5D-5L). Qual Life Res. 2011;20:1727-36.

3. Stolk E, Ludwig K, Rand K, van Hout B, Ramos-Goñi JM. Overview, update, and lessons learned from the international EQ-5D-5L valuation work: version 2 of the EQ-5D-5L valuation protocol. Value Health. 2019;22(1):23-30.

4. Pullenayegum EM, Perampaladas K, Gaebel K, Doble B, Xie F. Between-country heterogeneity in EQ-5D-3L scoring algorithms: how much is due to differences in health state selection? Eur J Health Econ. 2015;16(8):847-55.

5. Xie F, Gaebel K, Perampaladas K, Doble B, Pullenayegum E. Comparing EQ-5D valuation studies: a systematic review and methodological reporting checklist. Med Decis Making. 2014;34(1):8-20.
6. Devlin NJ, Shah KK, Feng Y, Mulhern B, van Hout B. Valuing health-related quality of life: an EQ-5D-5L value set for England. Health Econ. 2018;27:7-22.

7. Hernández-Alava M, Pudney S, Wailoo A. Quality review of a proposed EQ-5D-5L value set for England. Policy Research Unit in Economic Evaluation of Health \& Care Interventions (EEPRU) Report October 2018. Available from: https://www.eepru.org.uk/ wp-content/uploads/2017/11/eepru-report-eq-5d-51-27-11-18final.pdf. Accessed 17 Dec 2019.

8. Weinstein MC, Torrance G, McGuire A. QALYs: the basics. Value Health. 2009;12(Suppl. 1):S5-9.

9. National Institute for Health and Care Excellence (NICE). Guide to the methods of technology appraisal. 2013. London: NICE; 2013. Available from: https://www.nice.org.uk/process/pmg9/ chapter/foreword. Accessed 17 Dec 2019.

10. The Dental and Pharmaceutical Benefits Agency (TLV). General guidelines for economic evaluations from the Pharmaceutical Benefits Board LFNAR 2003:2. Stockholm: TLV; 2003. Available from: https://www.tlv.se/download/18.2e53241415e842c e95514e9/1510316396792/Guidelines-for-economic-evaluation s-LFNAR-2003-2.pdf. Accessed 17 Dec 2019.

11. The Dental and Pharmaceutical Benefits Agency (TLV). Ändring i Tandvårds- och läkemedelsförmånsverkets allmänna råd (TLVAR 2003:2) om ekonomiska utvärderingar (in Swedish). [Changes in the Dental and Pharmaceutical Benefits Agency's guidance for economic evaluations]. Stockholm: TLV; 2017. Available from: https://tlv.se/download/18.467926b615d084471ac3230c/15103 16374332/TLVAR 2017_1.pdf. Accessed 17 Dec 2019.

12. Dolan P. Modeling valuations for EuroQol health states. Med Care. 1997;35(11):1095-108.

13. Burström K, Sun S, Gerdtham UG, Henriksson M, Johannesson M, Levin LA. Swedish experience-based value sets for EQ-5D health states. Qual Life Res. 2014;23:431-42.

14. Cubi-Molla P, Shah K, Burström K. Experience-based values: a framework for classifying different types of experience in health valuation research. Patient. 2018;11(3):253-70.

15. Leidl R, Reitmeir P. A value set for the EQ-5D based on experienced health states: development and testing for the German population. Pharmacoeconomics. 2011;29(6):521-34.

16. Sun S, Chen J, Kind P, Xu L, Zhang Y, Burström K. Experience-based VAS values for EQ-5D-3L health states in a national general population health survey in China. Qual Life Res. 2015;24(3):693-703.

17. Leidl R, Reitmeir P. An experience-based value set for the EQ5D-5L in Germany. Value Health. 2017;20(8):1150-6.

18. Versteegh MM, Brouwer WBF. Patient and general public preferences for health states: a call to reconsider current guidelines. Soc Sci Med. 2016;165:66-74.

19. CDUST Region 2018. Liv \& hälsa 2017 i Mellansverige: resultat från en undersökning om livsvillkor, levnadsvanor och hälsa (in Swedish). [Life and health 2017: results from a survey on living conditions, health-related behaviors and health]. Available from: https://www.regionorebrolan.se/Files-sv/Örebro\%201äns\%20 landsting/Vård\%20och\%20hälsa/Folkhälsa/Liv\%20och\%20 hälsa\%20vuxna/Rapporter/Liv_halsa_i_Mellansverige\% 202017. pdf?epslanguage $=$ sv. Accessed 17 Dec 2019.

20. Dolan P. Thinking about it: thoughts about health and valuing QALYs. Health Econ. 2011;20(12):1407-16.

21. Burström K, Johannesson M, Diderichsen F. A comparison of individual and social time trade-off values for health states in the general population. Health Policy. 2006;76:359-70.

22. Bardage C, Isacson D, Ring L, Bingefors K. A Swedish population-based study on the relationship between the SF-36 and health utilities to measure health in hypertension. Blood Press. 2003;12(4):203-10. 
23. Lundberg L, Johannesson M, Isacson DG, Borgquist L. Healthstate utilities in a general population in relation to age, gender and socioeconomic factors. Euro J Public Health. 1999;3:211-7.

24. Chai T, Draxler RR. Root mean square error (RMSE) or mean absolute error (MAE)? Arguments against avoiding RMSE in the literature. Geosci Model Dev. 2014;7:1247-50.

25. Sammut C, Webb GI, editors. Mean absolute error. Encyclopedia of machine learning. Boston (MA): Springer; 2011. Available from: https://doi.org/10.1007/978-0-387-30164-8_525. Accessed 17 Dec 2019

26. Willmott CJ, Matsuura K. Advantages of the mean absolute error (MAE) over the root mean square error (RMSE) in assessing average model performance. Clim Res. 2005;30:79-82.

27. Wooldridge JM. Inverse probability weighted M-estimators for sample selection, attrition, and stratification. Port Econ J. 2002;1(2):117-39.

28. Versteegh MM, Vermeulen KM, Evers SMAA, de Wit GA, Prenger R, Stolk EA. Dutch tariff for the five-level version of EQ-5D. Value Health. 2016;19:343-52.

29. Ludwig K, Graf von der Schulenburg J-M, Greiner W. German value set for the EQ-5D-5L. Pharmacoeconomics. 2018;36:663-74

30. Hobbins A, Barry L, Kelleher D, Shah K, Devlin N, Goni JMR, et al. Utility values for health states in Ireland: a value set for the EQ-5D-5L. Pharmacoeconomics. 2018;36:1345-53.

31. Ramos-Goñi JM, Craig BM, Oppe M, Ramallo-Fariña Y, PintoPrades JL, Luo N, et al. Handling data quality issues to estimate the Spanish EQ-5D-5L value set using a hybrid interval regression approach. Value Health. 2018;21:596-604.

32. Helgesson G, Ernstsson O, Åström M, Burström K. Whom should we ask? A systematic literature review of the arguments regarding the most accurate source of information for valuation of health states. Qual Life Res. 2020. https://doi.org/10.1007/s11136-02002426-4.
33. Wolff J, Edwards S, Richmond S, Orr S, Rees G. Evaluating interventions in health: a reconciliatory approach. Bioethics. 2012;26(9):455-63.

34. Dolan P. NICE should value real experiences over hypothetical opinions. Nature. 2009;462(7269):35.

35. Dolan P, Kahneman D. Interpretations of utility and their implications for the valuation of health. Econ J. 2008;118:215-34.

36. Brazier J, Akehurst R, Brennan A, Dolan P, Claxton K, McCabe $\mathrm{C}$, et al. Should patients have a greater role in valuing health states? Appl Health Econ Health Policy. 2005;4(4):201-8.

37. Emilsson L, Lindahl B, Köster M, Lambe M, Ludvigsson JF. Review of 103 Swedish healthcare quality registries. J Intern Med. 2015;277:94-136.

38. Stamuli E. Health outcomes in economic evaluation: who should value health? Br Med Bull. 2011;97:197-210.

39. Happich M, von Lengerke T. Valuing the health state 'tinnitus': differences between patients and the general public. Hear Res. 2005;207:50-8.

40. Ubel PA, Loewenstein G, Jepson C. Whose quality of life? A commentary exploring discrepancies between health state evaluations of patients and the general public. Qual Life Res. 2003;12:599-607.

41. Ogorevc M, Murovec N, Fernandez NB, Rupel VP. Questioning the differences between general public vs. patient based preferences towards EQ-5D-5L defined hypothetical health states. Health Policy. 2019;123(2):166-72.

42. Ubel PA, Nord E, Gold M, Menzel P, Prades JL, Richardson J. Improving value measurement in cost-effectiveness analysis. Med Care. 2000;38(9):892-901.

43. Leidl R. Zum Beitrag der gesundheitsökonomischen Forschung zur medizinischen Versorgung [in German]. [On the contribution of health economic research to medical care] (abstract in English). Gesundh ökon Qual Manag. 2018;23(3):159-65.

\section{Affiliations}

\section{Kristina Burström ${ }^{1,2}\left(\right.$ Fitsum Sebsibe Teni $^{1}\left(\mathbb{D} \cdot\right.$ Ulf-G. Gerdtham $^{3,4}\left(\mathbb{D} \cdot\right.$ Reiner LeidI $^{5,6}\left(\mathbb{D} \cdot\right.$ Gert Helgesson $^{7}(\mathbb{D})$ Ola Rolfson ${ }^{1,8,9,10} \mathbb{B}^{-}$. Martin Henriksson ${ }^{11}[$}

1 Health Outcomes and Economic Evaluation Research Group, Stockholm Centre for Healthcare Ethics, Department of Learning, Informatics, Management and Ethics, Karolinska Institutet, Tomtebodavägen 18a, 17177 Stockholm, Sweden

2 Equity and Health Policy Research Group, Department of Global Public Health, Karolinska Institutet, Stockholm, Sweden

3 Department of Economics, Lund University, Lund, Sweden

4 Health Economics Unit, Department of Clinical Sciences in Malmö, Lund University, Lund, Sweden

5 Institute for Health Economics and Health Care Management, Helmholtz Zentrum München, German Research Center for Environmental Health, Neuherberg, Germany

6 Munich Center of Health Sciences, Ludwig-Maximilians University, Munich, Germany
7 Medical Ethics Research Group, Stockholm Centre for Healthcare Ethics, Department of Learning, Informatics, Management and Ethics, Karolinska Institutet, Stockholm, Sweden

8 Department of Orthopaedics, Institute of Clinical Sciences, Sahlgrenska Academy, University of Gothenburg, Gothenburg, Sweden

9 Sahlgrenska University Hospital, Gothenburg, Sweden

10 Swedish Hip Arthroplasty Register, Centre of Registers Västra Götaland, Gothenburg, Sweden

11 Center for Medical Technology Assessment, Department of Medical and Health Sciences, Linköping University, Linköping, Sweden 